\title{
A potencialidade do lodo de esgoto como componente de substrato para mudas de espécies florestais
}

\author{
Samya de Freitas Moreira ${ }^{a}$, Sara Dorea de Oliveira Santos ${ }^{a}$, Antônio Pereira Júnior ${ }^{\mathrm{a}}$ (D) \\ aUniversidade do Estado do Pará (UEPA), Laboratório de Qualidade Ambiental - Campus VI, Paragominas - PA, Brasil.
}

RESUMO Dentre as diversas formas existentes de disposição final do lodo de esgoto, a reciclagem florestal é uma das mais promissoras, por este ser um resíduo que constitui fonte de matéria orgânica $(\mathrm{MO})$ e nutrientes essências para as plantas, dentre eles, o nitrogênio (N), fósforo (P) e o potássio (K). Diante disso, teve-se como objetivo, estudar a potencialidade do lodo de esgoto como componente de substrato para mudas de espécies florestais, ao considerar as propriedades físico-químicas e microbiológicas do lodo produzido por uma Estação de Tratamento de Esgoto (ETE) do município de Paragominas - PA. O método aplicado foi o dedutivo, com abordagem quantiqualitativa, associada a levantamento de dados documentais em periódicos científicos indexados entre 2010 a 2020, a fim de selecionar literaturas mais atuais. Quanto ao plano de amostragem do lodo estudado, ele envolveu as etapas estabelecidas pela ABNT. A análise dos dados possibilitou inferir que: 1$)$ o lodo analisado contém altos teores de $\mathrm{MO}(\bar{x}=86,55 \%)$, $\mathrm{N}_{\text {total }}(\bar{x}=2,02 \%), \mathrm{P}(\bar{x}=5,70 \%), \mathrm{C}$ org $(\bar{x}=24,29 \%)$, além de ter apresentado padrões microbiológicos conforme o exposto na Resolução CONAMA 375; 2) possui potencial para influenciar no bom desenvolvimento inicial de mudas florestais, no que diz respeito aos aspectos, como a relação Altura/Diâmetro do Coreto (H/DC) e Massa Seca da Parte Aérea (MSPA); e estes podem ainda contribuir para um bom Índice de Qualidade de Dickson (IQD). Desta forma, a composição de substratos formulados com o lodo de esgoto estudado pode auxiliar no desenvolvimento inicial de mudas florestais e, consequentemente, na sobrevivência delas na fase de campo.

PALAVRAS-CHAVE: disposição final; reciclagem florestal; resíduo.

Aceito 02 de Julho de 2020 Publicado online 14 de julho de 2020

Cite este artigo: Moreira et al (2020) A potencialidade do lodo de esgoto como componente de substrato para mudas de espécies florestais. Multidisciplinary Science Journal 2: e2020006, doi: 10.29327/multiscience.2020006.

\section{The potential of sewage sludge as a substrate component for seedlings of forest species}

ABSTRACT Among the various existing forms of final disposal of sewage sludge, a recycling forest is one of the most promising, for this is a waste that comes from the source of organic material (MO) and essential nutrients for plants, among them, or nitrogen $(\mathrm{N})$, phosphorus $(\mathrm{P})$ and potassium $(\mathrm{K})$. Therefore, the objective was to study the potential of sewage sludge as a substrate component for seedlings of forest species, when considering the physicochemical and microbiological properties of the sludge produced by a Sewage treatment station (ETE) in the municipality of Paragominas - PA. The applied method was deductive, with a quantitative and qualitative approach, associated with the collection of documentary data in scientific journals indexed between 2010 to 2020, to select more current literature. As for the sampling plan of the studied sludge, it involved the steps established by ABNT (2004). Data analysis made it possible to infer that: 1$)$ the analyzed mud contains high levels of OM $(\bar{x}=86.55 \%), \mathrm{N}_{\text {total }}(\bar{x}=2.02 \%), \mathrm{P}(\bar{x}=5.70 \%), \mathrm{C}$ $\operatorname{org}(\bar{x}=24.29 \%)$, in addition to presenting microbiological standards as set out in CONAMA Resolution 375 of 2006; 2 ) has the potential to influence the proper initial development of forest seedlings, concerning aspects, such as the Height/Bandstand Diameter (H/DC) ratio and Dry Mass of Aerial Part (MSPA). These can also contribute to a useful Dickson Quality Index (IQD). Therefore, the composition of substrates formulated with the studied sewage sludge can assist in the initial development of forest seedlings and, consequently, in their survival in the field phase.

KEYWORDS: final provision; forest recycling; residue. 


\section{Introdução}

O lodo de esgoto é um dos maiores passivos ambientais urbanos no Brasil corresponde à disposição final dos resíduos sólidos. Ele é caracterizado como um subproduto gerado nas Estações de Tratamento de Esgoto (ETE's) e que representa em torno de $1 \%$ a $2 \%$ do volume da água residuária captada e tratada (Nobrega et al 2017).

A problemática acerca da disposição final desse lodo, ocorre, principalmente, devido a duas características indesejáveis neste resíduo: presença de elementos tóxicos, como o alumínio (Al), mercúrio ( $\mathrm{Hg})$, chumbo ( $\mathrm{Pb})$, Ferro (Fe) e cádmio (Cd) e microrganismos patogênicos, a exemplo dos coliformes fecais, salmonela, ovos de helmintos e cistos de protozoários. Surge neste caso, a necessidade de dispor os lodos de esgoto de forma adequada à proteção do meio ambiente e à saúde da população (Saffari et al 2020; Zoghlami et al 2018).

Há diversas alternativas para realizar a disposição final deste composto orgânico, como o encaminhamento aos aterros sanitários, descarga oceânica e incineração. Além disso, ele pode ser aproveitado na área florestal de diferentes formas, desde substrato para produção de mudas florestais, condicionador de solos degradados, como fertilizante em plantios comerciais, na restauração florestal e em plantios de arborização urbana (Bringhenti et al 2018).

Sobre a produção de mudas de espécies florestais, ela consiste em uma das atividades mais importantes da silvicultura, pois representa o início de uma cadeia de operações que permite o estabelecimento de florestas e povoamentos, e têm como objetivos ambientais a recuperação de áreas degradadas e o reflorestamento de matas ciliares, por exemplo (Abreu et al 2019). No processo de produção de mudas de espécies florestais, a escolha de um substrato é crucial para produção de uma muda de qualidade, à medida que ele é definido como o meio adequado para a sustentação e retenção de água, oxigênio e nutrientes, além de oferecer potencial hidrogeniônico (pH) compatível e ausência de elementos químicos em níveis tóxicos (Nobrega et al 2017).

Partindo deste princípio, algumas pesquisas apontaram o uso do lodo de esgoto com perspectivas favoráveis para a produção de mudas florestais (Delarmelina et al 2014; Gomes et al 2013; Rocha et al 2013). Um dos aspectos mais promissores da utilização deste insumo para a composição de substratos, está no fato dele ser fonte de matéria orgânica $(\mathrm{MO})$, carbono orgânico $(\mathrm{C}$ org), nitrogênio $(\mathrm{N})$, fósforo $(\mathrm{P})$, potássio $(\mathrm{K})$, cálcio $(\mathrm{Ca})$ e magnésio $(\mathrm{Mg})$ como macronutrientes, além do cobre (Cu), zinco (Zn) e manganês (Mn), como micronutrientes (Zomer et al 2018). Em relação a esses elementos, parte deles é liberada gradativamente e atuarão de forma direta no desenvolvimento das mudas durante todo o ciclo de produção, de modo a suprir as necessidades nutricionais existentes (Bonini et al 2015).

Do ponto de vista financeiro, o uso do lodo para produção de mudas florestais pode ser uma opção vantajosa, ao considerar o alto custo dos substratos de origem mineral disponíveis atualmente no mercado. Em alguns casos, a economia pode chegar à ordem de $64 \%$ em relação ao substrato comercial fertilizado, o mais utilizado convencionalmente (Cabreira et al 2017; Nafez et al 2015).

Desta forma, tais argumentos justificam esta pesquisa, cuja relevância é incrementada pela elaboração de informações necessárias para estimular a reciclagem florestal do lodo. Assim sendo, o objetivo do trabalho é estudar a potencialidade deste insumo orgânico como componente de substrato para mudas de espécies florestais, ao considerar as propriedades físico-químicas e microbiológicas do lodo de esgoto produzido por uma ETE do município de Paragominas - PA.

\section{Limitações do uso lodo de esgoto na área florestal}

\section{Efeito tóxico}

A Resolução 375 de 2006 do Conselho Nacional do Meio Ambiente (CONAMA) estabelece na Seção IV, art. 12, a proibição do uso de qualquer classe de lodo de esgoto ou produto derivado em pastagens e cultivo de olerícolas, tubérculos e raízes, culturas inundadas, bem como as demais culturas cuja parte comestível entre em contato com o solo (Brasil 2006).

Essas recomendações rigorosas têm relação, principalmente, com a possibilidade de toxidez do solo devido a presença de metais pesados (Ex.: Al, $\mathrm{Hg}, \mathrm{Pb}$, Fe e $\mathrm{Cd}$ ). Tais elementos, além de exercerem efeitos negativos sobre as plantas, como a inibição do desenvolvimento radicular e diminuição da produtividade, também afetam os processos bioquímicos que ocorrem no solo, dentre eles a decomposição da MO, a mineralização do $\mathrm{N}$ e a nitrificação (Duan et al 2017; Sampaio et al 2012). 


\section{Mineralização lenta e excesso de Nitrogênio (N)}

A lenta mineralização do composto orgânico pode ser prejudicial sob o ponto de vista nutricional e produtivo, pois a consequente liberação dos nutrientes pode não ocorrer no momento em que a cultura mais necessita (estágio do crescimento). Desse modo, em certos casos, torna-se necessária uma complementação com fertilizantes minerais, para compensar a lenta mineralização e melhorar a fertilidade dos solos e a nutrição das plantas (Carvalho et al 2015).

Quanto ao N, por mais que este seja um elemento essencial para o crescimento e desenvolvimento das plantas e dos seres vivos no solo, a quantidade de lodo aplicado deve ser tal que a quantidade de nitrato ( $\mathrm{NO}^{3-}$ ) ou amônio $\left(\mathrm{NH}^{4+}\right)$ presente, não exceda aquela que a planta irá consumir, pois o excesso ficaria em forma lixiviável, com a possibilidade de alcançar e contaminar corpos de água subterrâneos. Isso porque a MO ao sofrer mineralização, libera $\mathrm{N}$ na forma nítrica e amoniacal que é somado ao existente antes da aplicação (Silva 2011).

\section{Material e Métodos}

Para elaboração desse estudo, aplicaram-se cinco sínteses redigidas por pesquisadores acerca das exposições sobre métodos de pesquisa (Tabela 1).

Tabela 1 Os métodos de pesquisa utilizados.

\begin{tabular}{|c|c|c|c|}
\hline Pesquisador & Ano da publicação & Métodos & Características \\
\hline Prodanov e Freitas & 2013 & Dedutivo & $\begin{array}{l}\text { A partir de duas premissas verdadeiras chega-se a uma } \\
\text { conclusão indiscutível. }\end{array}$ \\
\hline Matias-Pereira & 2016 & $\begin{array}{c}\text { Abordagem } \\
\text { quantiqualitativa }\end{array}$ & $\begin{array}{l}\text { A utilização conjunta da pesquisa quantitativa e qualitativa } \\
\text { permite coletar mais informações do que se poderia } \\
\text { conseguir isoladamente, ao gerar abrangência dos dados e } \\
\text { maior compreensão acerca dos problemas estudados. }\end{array}$ \\
\hline Ferreira & 2011 & Natureza aplicada & $\begin{array}{l}\text { Gera conhecimentos novos, orientados à solução de } \\
\text { problemas específicos ao envolver verdades e interesses } \\
\text { locais, com aplicação prática prevista. }\end{array}$ \\
\hline Severino & 2017 & $\begin{array}{l}\text { Procedimento } \\
\text { experimental }\end{array}$ & $\begin{array}{l}\text { Tem-se a determinação de um objeto de estudo, seleção } \\
\text { das variáveis capazes de influenciá-lo e a definição das } \\
\text { formas de controle e observação dos efeitos que a variável } \\
\text { produz no objeto. }\end{array}$ \\
\hline
\end{tabular}

Para o levantamento dos dados documentais, foram utilizados periódicos científicos disponíveis nas seguintes bases informacionais: (1) Coordenação de Pesquisa e Aperfeiçoamento do Ensino Superior (CAPES), (2) Science Eletronic Library Online (SicELO), (3) Google Scholar, (4) SciVerse Scopus e (5) WebScience. Os dados documentais foram indexados e alocados no recorte temporal para os últimos 10 anos (2010-2020), sendo 30\% de 2010-2014 e 70\% de 2015-2020. Isso ocorreu para selecionar literaturas mais atuais, com exceção para a utilização de 2 referências publicadas anteriormente ao período proposto: 2004, 2006 e 2009.

Com o intuito de favorecer a busca nas bases de dados, explorar literaturas que possam contribuir no embasamento desta pesquisa e evitar a repetição de publicações, adotaram-se quatro descritores e três condições para essas ações (Tabela 2).

Tabela 2 Descritores e condições adotados.

\begin{tabular}{cl}
\hline Descritores & \multicolumn{1}{c}{ Características } \\
\hline 1 & Composição do Lodo de ETE. \\
2 & Disposição final do lodo de ETE. \\
3 & Substratos orgânicos para mudas de espécies florestais. \\
4 & Uso do lodo de ETE em substratos de mudas de espécies florestais. \\
\hline Condições & \multicolumn{1}{c}{ Características } \\
\hline 1 & Informações específicas sobre o (s) autor (es). \\
3 & Ano da publicação (estudos publicados no período proposto). \\
& Existência de registros acadêmicos: (1) International Standard Book Number (ISBN), (2) \\
\end{tabular}




\section{Caracterização do lodo utilizado}

O lodo estudado foi gerado na ETE do condomínio "Morada do Sol", na zona urbana do município de Paragominas, localizado na mesorregião sudeste do estado do Pará (Figura 1). A área territorial deste município é de $19.342,254 \mathrm{~km}^{2}$ e a população é estimada em 111.764 habitantes (Souza et al 2017).

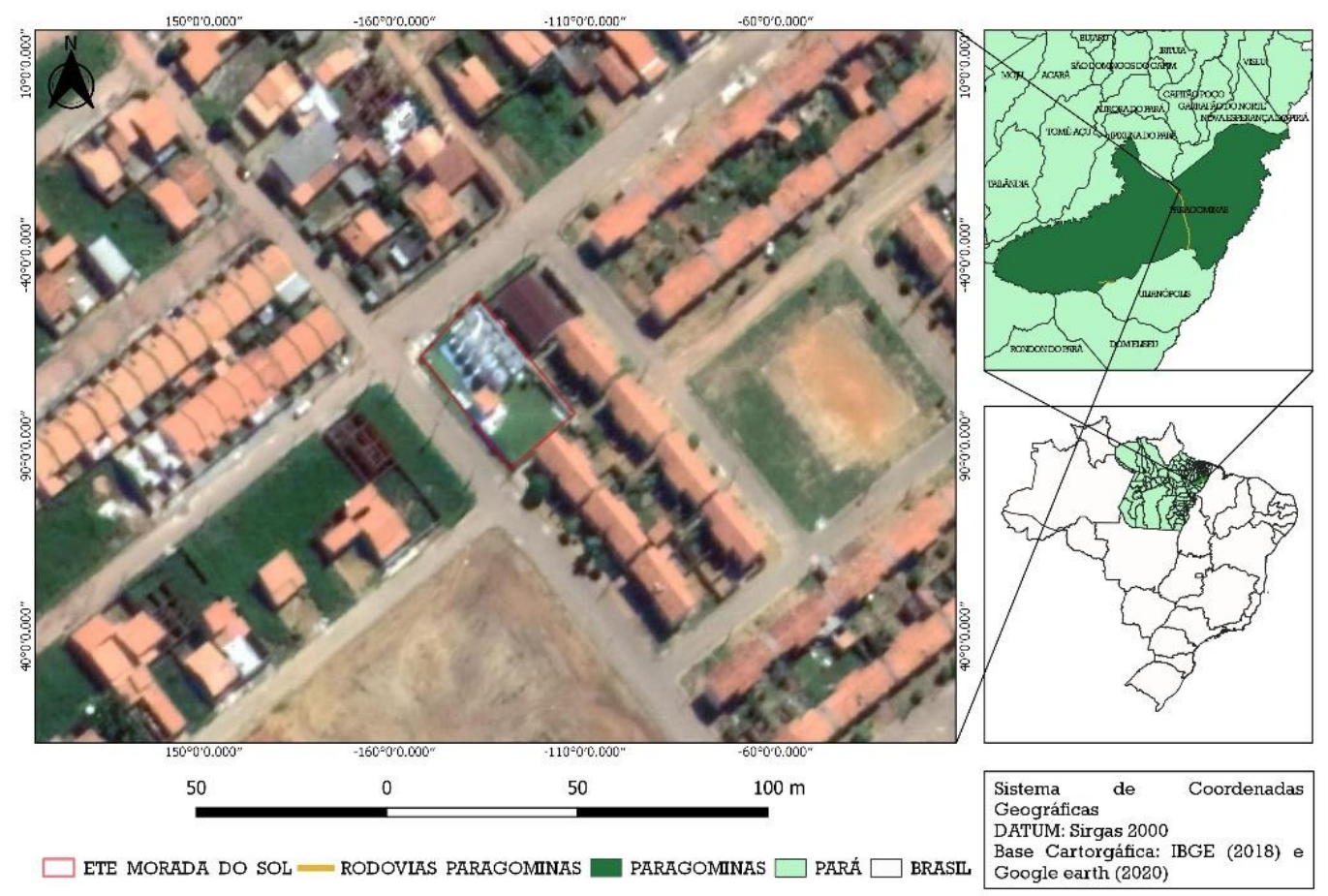

Figura 1 Localização da ETE do condomínio "Morada do Sol”. Paragominas - PA.

A ETE é receptora de efluentes sanitários, apresenta capacidade de atendimento para 5.000 pessoas, possui contribuição igual a $240 \mathrm{~L} /$ habitante/dia e suporta uma vazão equivalente a $445,44 \mathrm{~m}^{3} /$ dia. A respeito do processo de tratamento do lodo existente, ele é composto por três etapas: tratamento biológico do efluente em reator anaeróbico, redução da umidade do composto orgânico por processo de adensamento; estabilização do lodo de esgoto durante 30 dias em leito de secagem para a eliminação dos patógenos (Sanepar 2015).

\section{Amostragem do lodo - etapas}

A amostragem do lodo ocorreu após 30 dias de higienização em leito de secagem e envolveu as três etapas (Tabela 3) descritas pela ABNT (2004).

Tabela 3 Etapas do plano de amostragem do lodo de ETE.

\begin{tabular}{cl}
\hline Etapas & \multicolumn{1}{c}{ Ações } \\
\hline 1 & A superfície do leito de secagem foi dividida em 4 parcelas (A, B, C e D). \\
2 & Retirou-se três amostras representativas de cada parcela. \\
3 & As 12 amostras foram armazenadas em frascos de vidro esterilizados $(v=250 \mathrm{ml})$. \\
\hline
\end{tabular}

As amostras de lodo foram imediatamente identificadas com etiquetas e alocadas em caixa de poliestireno expandido (isopor) com $100 \mathrm{~L}$. Em seguida, elas foram encaminhadas ao Instituto Brasileiro de Análises (IBRA) para análise laboratorial, com o fim de determinar: cargas contaminantes; umidade; teores de carbono orgânico (C org), nitrogênio total ( $\left.\mathrm{N}_{\text {total }}\right), \mathrm{Fe}$, K e MO; etc.

\section{Resultados e Discussão}

A caracterização física, química e microbiológica do lodo gerado na ETE do condomínio "Morada do Sol" em Paragominas (PA), apresentou aspectos bem distintos (Tabela 4). 
Tabela 4 Análise física, química e microbiológica do lodo do ETE.

\begin{tabular}{|c|c|c|c|c|}
\hline \multicolumn{5}{|c|}{ Propriedades físico-químicas e microbiológicas do lodo de ETE } \\
\hline \multirow[b]{2}{*}{ Atributos } & \multicolumn{3}{|c|}{ Concentrações médias $(\bar{x})$} & \multirow[b]{2}{*}{ Unidades } \\
\hline & Física & Química & Microbiológica & \\
\hline Umidade $\left(65^{\circ} \mathrm{C}\right)$ & 34,48 & -- & - & $\%$ \\
\hline $\mathrm{pH}$ em $\mathrm{CaCl}_{2}$ & - & 6,80 & - & $*$ \\
\hline $\mathrm{P}$ & - & 5,70 & - & $\%$ \\
\hline $\mathrm{Ca}$ & - & 9,20 & - & $\%$ \\
\hline $\mathrm{Mg}$ & - & 5,52 & - & $\%$ \\
\hline $\mathrm{N}_{\text {total }}$ & - & 2,02 & - & $\%$ \\
\hline K & - & 1,46 & - & $\%$ \\
\hline $\mathrm{Fe}$ & - & 1,44 & - & $\%$ \\
\hline MO & - & 86,55 & - & $\%$ \\
\hline Corg & - & 24,29 & - & $\%$ \\
\hline Relação C/N & - & 12,00 & - & $*$ \\
\hline Cinzas & - & 13,45 & - & $\%$ \\
\hline Salmonella sp. & - & - & Ausência & $*$ \\
\hline $\begin{array}{l}\text { Ovos Viáveis de } \\
\text { Helmintos }\end{array}$ & - & - & Ausência & Ovo/g de ST \\
\hline $\begin{array}{l}\text { Coliformes } \\
\text { Termotolerantes }\end{array}$ & - & - & 16,45 & $\mathrm{NMP} / \mathrm{g}$ de ST \\
\hline
\end{tabular}

\section{Umidade do lodo}

O dado referente à umidade do lodo $(\bar{x}=34,48 \%)$ está diretamente relacionado ao processo de estabilização que ele recebeu, visto que, de acordo com o estudo de Souza et al (2019) efetuado no município de Seropédica - RJ, o maior aceleramento do crescimento, qualidade e biomassa das mudas de Açoita-cavalo (Luehea divaricata Mart.), ocorreu em resposta ao tipo de tratamento que o lodo utilizado recebeu. Sobre isso, os autores destacaram que o lodo estabilizado por secagem térmica, com menor teor de umidade (10\%), favoreceu a preservação de nutrientes e as frações biodegradáveis de carbono (C).

O teor de umidade ideal ao substrato deve ser mensurado de acordo com as exigências nutricionais de cada espécie florestal. No estudo de Alonso et al (2018) realizado no município de Seropédica - RJ, o lodo utilizado apresentava $30 \%$ de umidade, sendo que os substratos com altas proporções dele também resultaram em maior qualidade no crescimento das mudas de Paineira (Ceiba speciosa A. St.-Hil.). Neste caso, o lodo da ETE de Paragominas - PA pode ser utilizado em substratos de mudas florestais que demandem um maior teor de umidade para que se proceda o desenvolvimento inicial (Ex.: Eucalipto-rosa - Eucalyptus grandis W. Hill ex Maiden.).

$p H$

$\mathrm{O} \mathrm{pH}$ do lodo analisado $(\bar{x}=6,80 \%)$ é característico do processo de decomposição da MO nesse composto. Sobre isso, na pesquisa realizada por Cabreira et al (2017) no Rio de Janeiro - RJ, afirmaram que o substrato com faixa de pH ácido, no intervalo de 5,5 a 6,5, facilita a absorção de macronutrientes e micronutrientes para as mudas.

No lodo da ETE de Paragominas - PA, a faixa de pH encontra-se acima do intervalo citado. Dessa forma, deve-se considerar relevante acrescentar uma proporção de resíduo orgânico ao lodo, a fim de potencializar a absorção de nutrientes pelas mudas, o que foi efetuado por Santos et al (2014) no estudo delineado em São Gabriel - RS. Esses autores indicaram que o substrato composto somente pelo lodo de ETE apresentou um pH de 7,10 e, após a incorporação de cascas de arroz in natura, o resultado foi equivalente a 6,06 para este atributo. Ou seja, dentro do intervalo característico para a viabilidade nutricional das mudas $(5,5$ a 6,5).

\section{Concentração de Fósforo (P)}

$O$ alto teor de $\mathrm{P}(\bar{x}=5,70 \%)$ no composto orgânico pode ser vinculado às características do esgoto tratado, em decorrência das elevadas concentrações de resíduos orgânicos e produtos de limpeza. Nas mudas, este nutriente auxilia no arranque inicial do desenvolvimento a partir da emergência da plântula. Sobre isso, no estudo efetuado em Manaus 
- AM, Souza et al (2010) relataram que esse elemento foi limitante ao crescimento (altura e diâmetro) e à produção da Massa Seca da Parte Aérea (MSPA) e raiz da Acácia (Acacia magnium Willd.). Esse fato foi confirmado após o tratamento completo fosfatado obter valores superiores para as características citadas, em comparação ao tratamento com omissão de $P$.

No que se refere a este elemento como um agente auxiliador para o aumento da MSPA nas mudas florestais, isso foi comprovado por Delarmelina et al (2013) num estudo realizado em Alegre - ES. Os autores verificaram que os substratos com maiores proporções $(80 \%, 60 \%$ e $40 \%)$ de um lodo com fonte potencial de $P(4,08 \%)$ apresentaram os maiores valores de MSPA (2,225\%, 2,505\% e 2,477\%, respectivamente) nas mudas de Cambaí-amarelo (Sesbania virgata Cav.).

No tocante ao lodo de ETE de Paragominas - PA, este apresenta-se como um bom componente para substratos de mudas florestais. Isto corrobora com o estudo de Abreu et al (2017), visto que em pesquisa realizada no município de Seropédica - RJ, os substratos com a incorporação do lodo de esgoto apresentaram maior teor de P. Tal fato favoreceu o crescimento das mudas de Aroeira-vermelha (Schinus terebinthifolius Raddi.) e Ipê-rosa (Handroanthus heptaphyllus Vell.), com níveis deste elemento dosados de acordo com as exigências nutricionais de cada espécie.

\section{Concentração de Cálcio (Ca) e Magnésio (Mg)}

As concentrações de Ca $(\bar{x}=9,20 \%)$ e $M g(\bar{x}=5,52 \%)$ podem ter os níveis elevados em decorrência da degradação da $\mathrm{MO}$ presente no lodo. A esse respeito, em pesquisa realizada no município de Petrolina - PE, Pereira (2019) destacou que não há um padrão definido para os teores desses macronutrientes secundários. Além disso, o autor reitera a importância deles para o desenvolvimento vegetal, visto que são responsáveis pela rigidez da parede celular por serem o centro da molécula de clorofila e por participarem da síntese proteica.

Com relação aos teores de Ca e Mg presente no lodo a partir da degradação da MO, Slorgon et al (2011), em pesquisa efetuada no município Santa Maria - RS, observaram que a presença de tais elementos no lodo utilizado aumentaram significativamente a massa radicular da muda de Angico-vermelho (Parapiptadenia rígida (Benth.) Brenan) após a incorporação de proporções (20\%, 40\% e 60\%, respectivamente) do insumo orgânico no substrato de adução das mudas. Tal fato revela que o lodo de Paragominas - PA pode auxiliar no desenvolvimento radicular e no aumento da capacidade de sobrevivência das mudas em campo.

\section{Concentração de Nitrogênio Total ( $\left.N_{\text {total }}\right)$}

O nível significante de $\mathrm{N}_{\text {total }}$ presente no lodo de esgoto $(\bar{x}=2,02 \%)$ pode ser decorrente da degradação da $\mathrm{MO}$ e mineralização dos nutrientes liberados. Juntamente com o $\mathrm{P}$, o $\mathrm{N}_{\text {total }}$ é fundamental para o bom desenvolvimento inicial das mudas, principalmente no crescimento da parte aérea, pois resulta em valores elevados para altura e diâmetro delas, conforme ocorreu no estudo de Cabreira et al (2017), realizado na cidade do Rio de Janeiro - RJ, com as mudas de Dedaleiro (Lafoensia pacari A. St.-Hil.).

A relação positiva entre a interação do $N$ total e $P$ foi confirmada no estudo efetuado por Santos et al (2019) no município de São Gabriel - RS, em que os autores obtiveram correlação forte $(r=0,78)$ entre tais elementos, com teores de $\mathrm{N}_{\text {total }}$ e P iguais a $2,30 \%$ e 5,20\%, respectivamente, verificados no lodo analisado. À vista disso, pode-se inferir que o lodo proveniente da ETE de Paragominas apresenta um bom potencial para auxiliar no crescimento inicial de mudas florestais, uma vez que possui teores de $\mathrm{N}$ total $(\bar{x}=2,02 \%)$ e $\mathrm{P}(\bar{x}=5,70 \%)$, próximos aos encontrados no estudo supracitado.

Os altos teores de N e P no lodo proveniente do condomínio "Morada do Sol" em Paragominas - PA, pode favorecer a relação entre Altura/Diâmetro do Coleto (H/DC) das mudas, caso este insumo seja utilizado como substrato. Sobre isso, na pesquisa realizada em Alegre - ES por Faria et al (2013), foi observado que em todos os tratamentos compostos por $80 \%$ de lodo de esgoto, obteve-se resultados positivos para as duas principais características morfológicas (altura da parte aérea e diâmetro do coleto) das mudas de Fedegoso-gigante (Senna alata L.), o que foi explicado pelos níveis consideráveis de N $(3,67 \%)$ e P $(5,09 \%)$ no lodo utilizado.

Concentração de Potássio (K) 
O baixo teor de $\mathrm{K}$ no lodo de ETE ( $\bar{x}=1,46 \%)$ pode estar relacionado com a solubilidade deste elemento, visto que durante o processo de tratamento de esgoto, o K permanece solúvel em água e não decanta para formar o lodo de fundo. A respeito da disponibilidade desse elemento em substratos, Trazzi et al (2014), em pesquisa desenvolvida em Alegre - ES, ressaltaram que há uma competição entre os macronutrientes $\mathrm{K}$ e $\mathrm{N}_{\text {total, }}$ pois foi observado que as mudas de Teca (Tectona grandis L. f.) apresentaram menor absorção de K quando adubadas com substratos que detinham maiores doses de $\mathrm{N}_{\text {total }}$.

Com o intuito de incrementar o teor $\mathrm{K}$ no substrato composto por biossólido de ETE, em estudo efetuado no município de São Gabriel -RS, Santos et al (2014) indicaram que acrescentar proporções de resíduos no substrato, como a casca de arroz carbonizada ou in natura, viabiliza o aumento de $K$, dada à importância deste nutriente para o crescimento do diâmetro do coleto e engrossamento do caule das mudas. Deste modo, o resíduo sugerido pode aumentar o potencial da oferta de K de um substrato composto pelo lodo de esgoto da ETE de Paragominas - PA.

\section{Concentração de Ferro (Fe)}

A concentração de Fe indicada $(\bar{x}=1,44 \%)$ pode estar associada ao $\mathrm{pH}$ desse composto $(\bar{x}=6,80)$, pois em pesquisa efetuada por Ludwig et al (2014) no município de Botucatu - SP, foi destacado que a maior disponibilidade desse elemento ocorre no intervalo de $\mathrm{pH}$ entre 3,0 e 6,5. Tal fato explica o baixo teor de Fe (1,44\%) disponível no lodo estudado.

Em um estudo efetuado no município de Capão Bonito - SP, Navas et al (2016) explanaram que a deficiência de Fe pode ocasionar o crescimento lento das mudas e diminuir a produtividade. Dessa forma, com o intuito de enquadrar o lodo de esgoto de Paragominas - PA no pH indicado e, consequentemente, aumentar a disponibilidade do Fe, os autores deste estudo recomendam a aplicação de corretivos de acidez ou a adição de resíduos orgânicos como, por exemplo, a fibra de coco.

\section{Concentração de Matéria Orgânica (MO)}

Outra substância com alta concentração no lodo de esgoto é a $\mathrm{MO}(\bar{x}=86,55 \%)$, que pode ser resultante da característica do conteúdo orgânico no efluente recebido pela ETE de Paragominas - PA. De acordo com Faria et al (2013), em uma pesquisa realizada em Alegre - ES, o alto teor de MO no substrato, potencializada pela introdução do lodo de ETE, tende a alterar a forma de retenção de água, visto que ocasiona o decréscimo da densidade e aumento da porosidade total, bem como o aumento da capacidade de adsorção do substrato.

Além disso, a MO influencia o aumento no teor de nutrientes importantes para o desenvolvimento de mudas florestais, visto que induz a capacidade de troca catiônica (CTC) no solo. Sobre isso, em pesquisa realizada no Rio de Janeiro - RJ, Abreu et al (2019) verificaram que a degradação da MO influenciou na maior disponibilidade de $\mathrm{N}_{\text {total }}$ $(3,88 \%)$ e C org (28,7\%) para as mudas de Aroeira-vermelha (Schinus terebinthifolia Raddi.). Dessa forma, devido a MO ser a substância de maior teor no lodo da ETE de Paragominas - PA, a presença deste insumo orgânico em substratos, pode trazer resultados positivos semelhantes.

Com relação ao Diâmetro do Coleto (DC), o estudo realizado por Rocha et al (2013) no município Garça - SP, a partir da utilização de um substrato $100 \%$ composto por lodo de esgoto em mudas híbridas de Eucalipto-vermelho (Eucalyptus urophylla S. T. Blake.) com Eucalipto-rosa (Eucalyptus grandis W. Hill ex Maiden.), os autores obtiveram para essa característica, o maior valor $(3,4 \mathrm{~mm})$ no final do experimento. Ainda de acordo com este estudo, os substratos com proporção de lodo acima de $40 \%$ promoveram o maior crescimento vegetativo das mudas, em decorrência da maior disponibilidade de nutrientes ocasionada pela degradação da MO. Ao considerar o elevado teor de MO, o lodo proveniente da ETE de Paragominas pode indicar um bom padrão de qualidade de mudas no que se refere ao DC.

\section{Concentração de Carbono orgânico (C org)}

Acerca da disponibilidade de $C$ org no lodo de esgoto $(\bar{x}=24,29 \%)$, ela é diretamente relacionada com o teor de $\mathrm{MO}(\bar{x}=86,55 \%)$ no meio. No tocante a esse assunto, a pesquisa de Caldeira et al (2014) em Alegre - ES, discorreu que o alto teor de C org no substrato auxiliou muito no desenvolvimento inicial das mudas de Acácia (Acacia mangium 
Wild.), pois beneficiou a absorção de nutrientes essenciais ao crescimento $\left(\mathrm{N}_{\text {total, }} \mathrm{P}\right.$ e K), como também promoveu a melhor penetração das raízes no solo e a maior capacidade tampão do substrato.

Dito isto, o lodo de esgoto analisado neste estudo contém as principais características para auxiliar a fase inicial de desenvolvimento da muda florestal, visto que o alto teor de $\mathrm{MO}(\bar{x}=86,55 \%)$ influenciou na maior disponibilidade de $C$ org $(\bar{x}=24,29 \%), \mathrm{P}(\bar{x}=5,70 \%)$ e $\mathrm{N}_{\text {total }}(\bar{x}=2,02 \%)$. Essas características confirmam os resultados obtidos por Bonini et al - 2015, em estudo realizado no município de Selvíria - MS.

No que se refere ao Índice de Qualidade de Dickson (IQD), considerado um ótimo indicador de qualidade das mudas por utilizar valores de robustez (relação H/DC) e do equilíbrio da distribuição da biomassa (relação MSPA), sabese que quanto maior o valor de IQD, melhor é a qualidade da muda produzida. Sobre essa questão, o estudo de Gomes et al (2013) realizado no município de Alegre - ES, obteve valores médios do IDQ para as mudas de Teca (Tectona grandis L. f.) entre 0,93 e 1,97, em que o maior valor foi obtido por meio de concentrações elevadas de lodo de esgoto (90\% lodo $+10 \%$ subsolo), o qual apresentou um grande potencial para ofertar C org, perfazendo cerca de $28,87 \%$ da sua constituição. Em Paragominas - PA, o lodo de esgoto possui um valor correlato para este atributo $(\bar{x}=24,29 \%)$, o que pode fazer dele um insumo orgânico capaz de melhorar a qualidade de mudas florestais.

\section{Relação Carbono/Nitrogênio (C/N)}

A baixa relação entre carbono e nitrogênio $(C / N)$ verificada no lodo $(\bar{x}=12,00)$, encontra-se conforme o disposto na instrução normativa n. 25 do Ministério da Agricultura, Pecuária e Abastecimento de 2009 (Brasil 2009 ), em que a relação $\mathrm{C} / \mathrm{N}$ não pode ser superior a 12,00. Este dado pode ser associado ao processo de digestão anaeróbica do lodo, visto que serve de parâmetro para analisar o equilíbrio de consumo de nutrientes por organismos vivos, e deve ser comparada a proporção correta do consumo de $\mathrm{C}$ e $\mathrm{N}$ no início e no final do tratamento.

Este atributo caracteriza-se por ser o equilíbrio do substrato, que de acordo com o estudo de Da Ros et al (2015), desenvolvido no município de Santa Maria - RS, a menor relação C/N contribuiu para o bom desenvolvimento inicial das mudas de Eucalipto-cidra (Eucalyptus dunnii Maiden.) Essa relação indica haver maior disponibilidade de $\mathrm{N}_{\text {total }}$ no substrato, em decorrência da mineralização da fração orgânica nesse meio. Desse modo, o lodo de ETE de Paragominas tem a característica para apresentar o mesmo potencial no que tange à contribuição para o crescimento inicial de mudas florestais.

\section{Concentração de cinzas}

Acerca das cinzas contidas no lodo $(\bar{x}=13,45 \%)$, elas podem ser relacionadas com o teor de material inorgânico presente nesse composto. Com relação a esse assunto, a pesquisa desenvolvida por Lazzari (2014) no município de Vila Velha - ES, foi verificado um teor de cinza equivalente a $24,32 \%$ no lodo analisado, o que caracterizou um baixo teor de substâncias inorgânicas na composição deste resíduo.

O lodo da ETE de Paragominas - PA apresentou quantidade de cinzas abaixo do teor apresentado no estudo realizado em Vila Velha. Dessa forma, deduz-se que ele é composto por baixíssimos teores de substâncias inorgânicas. Assim, pode-se inferir que o lodo da ETE de Paragominas- PA, por conter baixos teores de substâncias inorgânicas, não apresenta riscos sanitários e não compromete a atividade biológica dos seres vivos no meio em que for incorporado.

\section{Caracterização microbiológica}

Com relação aos parâmetros microbiológicos analisados, o lodo produzido na ETE de Paragominas é enquadrado como classe $A$, uma vez que ele apresenta concentrações de patógenos conforme o indicado na Resolução CONAMA 375 (Brasil 2006): Coliformes Termotolerantes < $10^{3} \mathrm{NMP} / \mathrm{g}$ de ST (16,45 NMP/g de ST), Ovos Viáveis de Helmintos < 0,25 ovo/g de ST (ausente) e Salmonella sp. ausência em $10 \mathrm{~g}$ de ST (ausente), o que pode estar diretamente vinculado com as condições socioeconômicas e sanitárias do local de instalação da ETE, bem como dos métodos de tratamento aplicados no lodo. Do mesmo modo, no estudo de Abreu et al (2019) realizado no Rio de Janeiro - RJ, o lodo de esgoto analisado foi enquadrado na mesma classificação (classe A), com valores para Coliformes Termotolerantes (0,04 NMP/g de ST), Ovos Viáveis de Helmintos (menos de 0,01 ovos/g de ST) e Salmonella sp. (ausente), abaixo dos valores estabelecidos na norma vigente. 
Dessa forma, no que se refere aos padrões microbiológicos o lodo analisado em Paragominas - PA não apresenta risco de contaminação por organismos patogênicos. Assim sendo, ele possui condições sanitárias e ambientais para o reuso florestal, com viabilidade de ser incorporado ao solo como adubo orgânico, neste caso, como substrato para mudas florestais.

\section{Considerações finais}

De acordo com os parâmetros avaliados e ao considerar o disposto na Resolução 375/06 do CONAMA, o lodo de esgoto estudado em Paragominas - PA pode ser considerado viável (física, química e microbiologicamente) como componente de substratos de mudas de espécies florestais. O que sugere uma alternativa promissora para que as ETE's possam dar uma disposição final adequada ao resíduo gerado.

Os principais elementos do lodo que podem potencializar o substrato e auxiliar no desenvolvimento de mudas florestais são a $\mathrm{MO}(\bar{x}=86,55 \%), \mathrm{C}$ org. $(\bar{x}=24,29 \%), \mathrm{N}_{\text {total }}(\bar{x}=2,02 \%)$ e $\mathrm{P}(\bar{x}=5,70 \%)$, atributos essenciais a fertilidade do solo. Por outro lado, para os elementos que apresentaram teores pouco satisfatórios, como o $\mathrm{K}(\bar{x}=1,46 \%)$ e Fe $(\bar{x}=$ $1,44 \%$ ), a adição de outros resíduos orgânicos, bem como a fibra de coco e palha de arroz in natura, podem suplementar tais nutrientes, além de contribuir para o equilíbrio de algumas características físicas, como retenção de água no substrato.

Por fim, é importante atentar-se à presença de patógenos e elementos orgânicos e inorgânicos tóxicos. O efeito deles no solo e nas plantas, a médio e longo prazo, ainda são pouco conhecidos e poderão, se não monitorados, causar danos às culturas seguintes, bem como contaminar o solo e a água.

\section{Referências}

ABNT (2004) NBR 10007: Amostragem de resíduos sólidos. Disponível em: https://wp.ufpel.edu.br/residuos/files/2014/04/nbr10007-amostragem-de-resc3adduos-sc3b3lidos.pdf. Acesso em: 14 abril 2019.

Abreu AHM, Alonso JM, Melo LA, Leles PSS, Santos GR (2019) Caracterização de biossólidos e potencial de uso na produção de mudas de Schinus terebinthifolia Raddi. Revista Engenharia Sanitária e Ambiental 24:591-599.

Abreu AHM, Leles PSS, Melo LA, Oliveira RR, Ferreira DHAA (2017) Caracterização e potencial de substratos formulados com biossólido na produção de mudas de Schinus terebinthifolius Raddi. e Handroanthus heptaphyllus (Vell.) Mattos. Revista Ciência Florestal 27:1179-1190.

Alonso JM, Abreu AHM, Melo LA, Leles PSS, Cabreira GV (2018) Biosolids as substrate for the production of caiba speciosa seedlings. Revista Cerne 24:420-429.

Bonini SB, Alves MC, Montanari R (2015) Lodo de esgoto e adubação mineral na recuperação de atributos químicos de solo degradado. Revista Brasileira Agrícola e Ambiental 19:388-393.

Brasil (2006) Resolução 375, de 29 agosto de 2006. Disponível em: http://www2.mma.gov.br/port/conama/res/res06/res37506.pdf. Acesso em: 20 novembro 2019.

Brasil (2009) Instrução Normativa 25, de 23 de julho de 2009 . Disponível em: https://futurelegis.com.br/legislacao/56585/Instru\%C3\%A7\%C3\%A3o-Normativa-Sda-N\%C2\%BA-25-de-23-07-

2009\#: :text=23\%2D07\%2D2009-

,Instru\%C3\%A7\%C3\%A30\%20Normativa\%20Sda\%20N\%C2\%BA\%2025\%2C\%20de\%2023\%2D07\%2D2009,e\%20Biofertilizantes\%20D estinados\%20\%C3\%80\%20Agricultura.

Bringhenti JR, Boscov MEG, Piveli RP, Gunther WMR (2018) Codisposição de lodos de tratamento de esgotos em aterros sanitários brasileiros: aspectos técnicos e critérios mínimos de aplicação. Engenharia Sanitária e Ambiental 23:891-899.

Cabreira GV, Leles PSS, Alonso JM, Abreu AHM, Lopes NF, Santos GR (2017) Biossólido como componente de substrato para produção de mudas florestais. Floresta 47:165-176.

Caldeira MVW, Favalessa M, Gonçalves EO, Delarmelina WM, Santos FEV, Viera M (2014) Lodo de esgoto como componente de substrato para produção de mudas de Acácia mangium Wild. Revista Comunicata Scientiae 5:34-43.

Carvalho CS, Ribeirinho VS, Andrade CA, Grutzmacher P, Pires AMM (2015) Composição química da matéria orgânica de lodos de esgoto. Revista Brasileira de Ciências Agrárias 10:413-419.

Da Ros CO, Rex FE, Ribeiro IR, Kafer PS, Rodrigues AC, Silva RF, Somavilla L (2015) Uso de substrato compostado na produção de mudas de Eucalyptus dunnii e Cordia trichotoma. Revista Floresta e Ambiente 22:549-558. 
Delarmelina WM, Caldeira MVW, Faria JCT, Gonçalves EO (2013) Uso de lodo de esgoto e resíduos orgânicos no crescimento de mudas de Sesbania virgata (Cav.) Pers. Revista Agroambiente 7:184-192.

Delarmelina WM, Caldeira MVW, Faria JCT, Gonçalves EO, Rocha RLF (2014) Diferentes substratos para a produção de mudas de Sesbania virgata. Floresta e Ambiente 21:224-233.

Duan B, Zhang W, Zheng H, Wu C, Zhang Q, Bu Y (2017) Disposal situation of sewage sludge from municipal wastewater treatment plants (WWTPs) and assessment of the ecological risk of heavy metals for its land use in Shanxi, China. International Journal of Environmental Research and Public Health 14:823-835.

Faria JCT, Caldeira MVW, Delarmelina WM, Lacerda LC, Gonçalves EO (2013) Substratos à base de lodo de esgoto na produção de mudas de Senna alata. Revista Comunicata Scientiae 4:342-351.

Ferreira H (2011) Redação de Trabalhos Acadêmicos. Rio de Janeiro: Editora Rubio.

Gomes DR, Caldeira MVW, Delarmelina WM, Gonçalves EO, Trazzi PA (2013) Lodo de esgoto como substrato para produção de mudas de Tectona grandis L. Cerne 19:123-131.

Lazzari J (2014) Análise do potencial energético de lodos obtidos no tratamento de esgoto. Trabalho de Conclusão de Curso (Bacharelado em Engenharia Ambiental) - Universidade Tecnológica Federal do Paraná.

Ludwig F, Fernandes DM, Guerrero AC, Bôas RLV (2014) Características dos substratos na absorção de nutrientes e na produção de gérbera de vaso. Revista Horticultura Brasileira 32:184-189.

Matias-Pereira J (2016) Manual de metodologia da pesquisa científica. 4. ed. São Paulo: Atlas.

Nafez AH, Nikaeen M, Kadkhodaie S, Hatamzadeh M, Moghim S (2015) Sewage sludge composting: quality assessment for agricultural application. Environmental Monitoring and Assessment 187:2-9.

Navas R, Nunes JMC, Vasconcellos Junior JB (2016) Aplicação de ferro e silício na produção de mudas de eucalipto. Revista Agrarian 9:137-142.

Nobrega MAS, Pontes MS, Santiago EF (2017) Incorporação do lodo de esgoto na composição de substrato para produção de mudas nativas. Acta Biomedica Brasiliensia 8:43-55.

Pereira JS (2019) Reuso agrícola de biossólido em cultivo de mudas de Psidium guajava L. Dissertação (Mestrado em Engenharia Agrícola) - Universidade Federal do Vale São Francisco. Pernambuco, 2019.

Prodanov CC, Freitas EC (2013) Metodologia do trabalho científico: métodos e técnicas da pesquisa e do trabalho acadêmico. 2 . ed. Novo Hamburgo: Feevale.

Rocha JHT, Backes C, Diogo FA, Pascotto CB, Borelli K (2013) Composto de lodo de esgoto como substrato para mudas de eucalipto. Pesquisa Florestal Brasileira 33:27-35.

Saffari M, Saffari VR, Khabazzadeh H, Naghavi H (2020) Assessment of content and chemical forms of arsenic, copper, lead, and chromium in sewage sludge compost as affected by various bulking agents. Main Group Metal Chemistry 43:56-66.

Sampaio TF, Guerrini IA, Backes C, Heliodoro JCA, Ronchi HS, Tanganelli KM, Carvalho NC, Oliveira FC (2012) Lodo de esgoto na recuperação de áreas degradadas: efeito nas características físicas do solo. Revista Brasileira de Ciência do Solo 36:1637-1645.

Sanepar (2015) Sanepar inicia estudos para reciclagem agrícola do lodo de esgoto. Disponível em: https://saneparagominas.com.br/noticias/30/sanepar-inicia-estudos-para-reciclagem-agricola-do- lodo-de-esgoto/. Acesso em: 22 março 2020.

Santos FEV, Kunz SH, Caldeira MVW, Azevedo CHS, Rangel OJP (2014) Características químicas de substratos formulados com lodo de esgoto para produção de mudas florestais. Revista Brasileira ade Engenharia Agrícola e Ambiental 18:971-979.

Santos RP, Lemos A, Pedroso LD, Travessas AO (2019) Efeito do lodo de esgoto na produção e nutrição de mudas de angico-vermelho (Parapiptadenia rígida (Benth.) Brenan). Revista Ecologia e Nutrição Florestal 7:1-10.

Severino AJ (2017) Metodologia do trabalho científico. 6. ed. São Paulo: Cortez.

Silva LDB (2011) Utilização do lodo de esgoto na produção de mudas e no cultivo do eucalipto (Eucalyptus spp). Monografia (Graduação em Engenharia Florestal) - Universidade Federal Rural do Rio de Janeiro. Rio de Janeiro, 2011.

Slorgon JG, Rizk MC, Bergamasco R, Tavares CRG (2011) Avaliação da DQO e da relação C/N obtidas no tratamento anaeróbio de resíduos fruti-hortículas. Revista Acta Scientiarum Technology 33:421-424.

Souza CAS, Tucci CAF, Silva JF, Ribeiro WO (2010) Exigências nutricionais e crescimento de plantas mogno (Swietenia macrophylla King.). Revista Acta Amazonica 40:515-522.

Souza LM, Adami M, Lima AMM, Ramos WF (2017) Avaliação do uso e cobertura da terra em Paragominas e Ulianópolis - PA, utilizando dados do projeto terraclass. Revista Brasileira de Cartografia 69:421-431. 
Souza TJS, Alonso JM, Leles PSS, Abel ELS, Ribeiro JG, Santana JES (2019) Mudas de Luehea divaricata produzidas com biossólidos de duas estações de tratamento de esgoto. Revista Advances in Foresty Science 6:95-601.

Trazzi PA, Caldeira MVW, Reis EF, Silva AG (2014) Produção de mudas de Tectona grandis em substratos formulados com biossólido. Revista Cerne 20:93-302.

Zoghlami RI, Hamdi H, Boudabbous K, Hechmi S, Khelil MN, Jedici N (2018) Seasonal toxicity variation in light-textured soil amended with urban sewage sludge: interaction effect on cadmium, nickel, and phytotoxicity. Environmental Science and Pollution Research 25:3608-3615.

Zomer JA, Ely C, Comelli RU, Alves MV, Skoronski E (2018) Lodo de Estação de Tratamento de Esgoto como fertilizante no cultivo de fumo e aveia. Revista em Agronegócio e Meio Ambiente 11:185-201. 